\title{
Function and cancer genomics of FAT family genes (Review)
}

\author{
MASARU KATOH \\ Division of Integrative Omics and Bioinformatics, National Cancer Center, Tokyo 104-0045, Japan \\ Received September 23, 2012; Accepted October 11, 2012
}

DOI: $10.3892 /$ ijo.2012.1669

\begin{abstract}
FAT1, FAT2, FAT3 and FAT4 are human homologs of Drosophila Fat, which is involved in tumor suppression and planar cell polarity (PCP). FAT1 and FAT4 undergo the first proteolytic cleavage by Furin and are predicted to undergo the second cleavage by $\gamma$-secretase to release intracellular domain (ICD). Ena/VAPS-binding to FAT1 induces actin polymerization at lamellipodia and filopodia to promote cell migration, while Scribble-binding to FAT1 induces phosphorylation and functional inhibition of YAP1 to suppress cell growth. FAT1 is repressed in oral cancer owing to homozygous deletion or epigenetic silencing and is preferentially downregulated in invasive breast cancer. On the other hand, FAT1 is upregulated in leukemia and prognosis of preB-ALL patients with FAT1 upregulation is poor. FAT4 directly interacts with MPDZ/MUPP1 to recruit membrane-associated guanylate kinase MPP5/PALS1. FAT4 is involved in the maintenance of PCP and inhibition of cell proliferation. FAT4 mRNA is repressed in breast cancer and lung cancer due to promoter hypermethylation. FAT4 gene is recurrently mutated in several types of human cancers, such as melanoma, pancreatic cancer, gastric cancer and hepatocellular carcinoma. FAT1 and FAT4 suppress tumor growth via activation of Hippo signaling, whereas FAT1 promotes tumor migration via induction of actin polymerization. FAT1 is tumor suppressive or oncogenic in a context-dependent manner, while FAT4 is tumor suppressive. Copy number aberration, translocation and point mutation of FAT1, FAT2, FAT3, FAT4, FRMD1, FRMD6, NF2, WWC1, WWC2, SAV1, STK3, STK4, MOB1A, $M O B 1 B, L A T S 1, L A T S 2, Y A P 1$ and WWTR1/TAZ genes should be comprehensively investigated in various types of human cancers to elucidate the mutation landscape of the FAT-Hippo signaling cascades. Because YAP1 and WWTR1 are located at the crossroads of adhesion, GPCR, RTK and stem-cell signaling network, cancer genomics of the FAT signaling cascades could be applied for diagnostics, prognostics and therapeutics in the era of personalized medicine.
\end{abstract}

Correspondence to: Dr Masaru Katoh, National Cancer Center, Division of Integrative Omics and Bioinformatics, 5-1-1 Tsukiji, Chuo Ward, Tokyo 104-0045, Japan

E-mail: mkatoh-kkr@umin.ac.jp

Key words: FAT, YAP, TAZ, actin dynamics, G-protein-coupled receptor, receptor tyrosine kinase, WNT, $\beta$-catenin, cancer stem cells, whole-genome sequence

\section{Contents}

1. Introduction

2. FAT family

3. Processing of FAT proteins

4. Signaling and function of FAT1 and FAT4

5. Cancer genomics of FAT family genes

6. Conclusion

7. Perspectives

\section{Introduction}

Drosophila mutants of the fat, discs large (dlg), lethal giant larvae (lgl), warts, scribble, salvador and hippo genes show tissue overgrowth (1-7). Overgrowth mutants of fat, warts, salvador and hippo are characterized by hyperplastic tumors mostly retaining single-layered epithelial structure, whereas those of scribble, $d l g$ and $l g l$ are characterized by neoplastic tumors losing epithelial structure $(8,9)$. Drosophila fat gene is genetically upstream of the warts, salvador and hippo genes, which are involved in the repression of Yokie-Scalloped-dependent transcription of cyclin $E$ and diapl genes (10-13). Because cyclin $E$ and diapl genes encode cell cycle accelerator and apoptosis inhibitor, respectively, loss-of-function mutations of Drosophila fat gene give rise to hyperplastic tumors through increased cell proliferation and decreased cell death (Fig. 1A).

In addition to tumor suppression, Drosophila fat gene is involved in planar call polarity (PCP) (Fig. 1A). PCP is the cell polarity within the plane of epithelial tissues orthogonal to the apical-basal axis (14-17). PCP is established as a result of the asymmetrical localization of the Flamingo-Frizzled-Dishevelled-Diego complex and the Flamingo-Strabismus-Prickle complex of adjacent cells via homophilic interaction of extracellular cadherin-repeat region of Flamingo. Drosophila frizzled, dishevelled, diego, flamingo (starry night), strabismus (van Gogh) and prickle genes encode the core PCP components (18-20), while Drosophila fat, dachsous, four jointed, discs overgrown and dachs genes encode the additional or complementary PCP components (21-24).

Drosophila fat gene encodes a large transmembrane protein with 34 Cadherin repeats, 4 EGF-like domains and 2 Laminin G-like domains in the extracellular region (25). Fat protein belongs to the Cadherin superfamily, which is classified into the classical cadherin family, Flamingo/Celsr family, Fat/Dachsous family and others $(26,27)$. Extracellular regions 
A

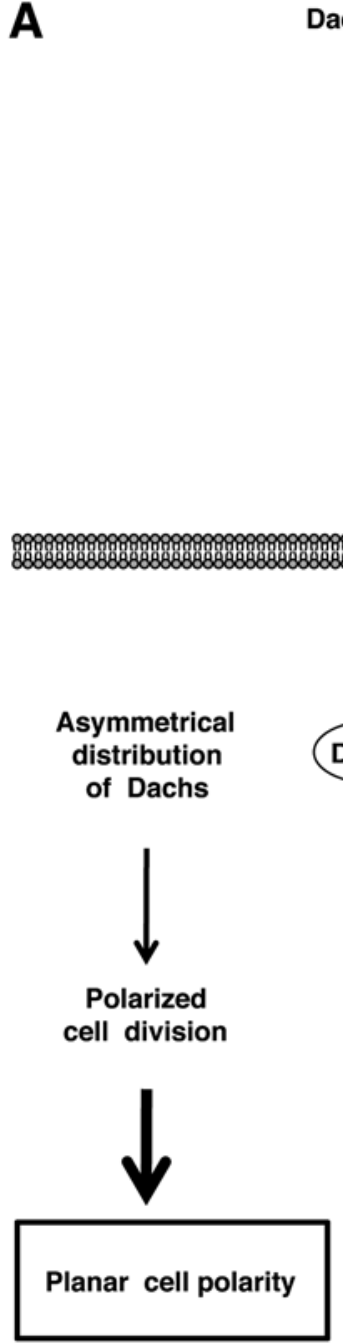

Dachsous

Fat

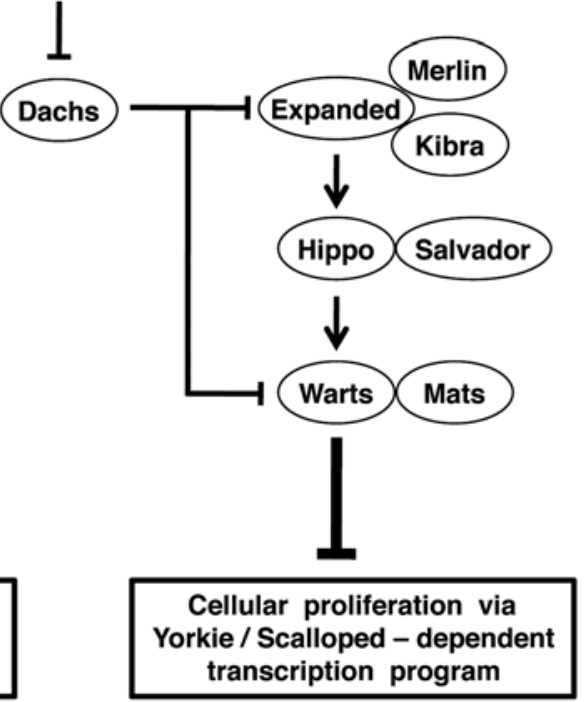

B

\begin{tabular}{|c|c|c|c|}
\hline Human gene & $\begin{array}{c}\text { Chromosomal } \\
\text { localization }\end{array}$ & $\begin{array}{c}\text { Drosophila } \\
\text { protein }\end{array}$ & Features \\
\hline FAT4 & $4 \mathrm{q} 28.1$ & Fat & \multirow{3}{*}{$\begin{array}{l}\text { Type I transmembrane } \\
\text { protein belonging to the } \\
\text { Cadherin superfamily }\end{array}$} \\
\hline $\begin{array}{l}\text { FAT1 } \\
\text { FAT2 } \\
\text { FAT3 }\end{array}$ & $\begin{array}{r}4 q 35.2 \\
5 q 33.1 \\
11914.3\end{array}$ & Fat-like & \\
\hline $\begin{array}{l}\text { DAFH 1 } \\
\text { DCHS2 }\end{array}$ & $\begin{array}{c}11 \mathrm{q} 14.3 \\
1 \mathrm{p} 15.4 \\
4 \mathrm{q} 31.3\end{array}$ & Dachsous & \\
\hline FJX1 & $11 \mathrm{p} 13$ & Fourjointed & Serine/threonine kinase \\
\hline & & Dachs & Myosin family protein \\
\hline $\begin{array}{l}\text { FRMD1 } \\
\text { FRMD6 }\end{array}$ & $\begin{array}{c}6 \mathrm{qq} 27 \\
14 \mathrm{q} 22.1\end{array}$ & Expanded & \multirow{2}{*}{ FERM-domain protein } \\
\hline NF2 2 & 22912.2 & Merlin & \\
\hline $\begin{array}{l}\text { WWC1 } \\
\text { WWC2 }\end{array}$ & $\begin{array}{c}5 \mathrm{q} 34 \\
4 \mathrm{q} 35.1\end{array}$ & Kibra & \multirow[t]{2}{*}{ WW-domain protein } \\
\hline SAV1 & $14 \mathrm{q} 22.1$ & \begin{tabular}{|l} 
Salvador \\
\end{tabular} & \\
\hline $\begin{array}{l}\text { STK3 (MST2) } \\
\text { STK4 (MST1) }\end{array}$ & $\begin{array}{c}8 \mathrm{q} 22.2 \\
20 \mathrm{q} 13.12\end{array}$ & Hippo & \multirow[t]{2}{*}{ Serine/threonine kinase } \\
\hline $\begin{array}{l}\text { LATS1 } \\
\text { LATS2 }\end{array}$ & $\begin{array}{c}6 q 25.1 \\
13 q 12.11\end{array}$ & Warts & \\
\hline $\begin{array}{l}\text { MOB1A } \\
\text { MOB1B }\end{array}$ & $\begin{array}{l}2 \mathrm{p} 13.1 \\
4 \mathrm{q} 13.3\end{array}$ & Mats & MOB kinase activator \\
\hline $\begin{array}{l}\text { YAP1 } \\
\text { WWTR1 (TAZ) }\end{array}$ & $\begin{array}{l}11 \mathrm{q} 22 \\
3 \mathrm{q} 25.1\end{array}$ & Yorkie & $\begin{array}{l}\text { WW-domain containing } \\
\text { transcriptional co-activator }\end{array}$ \\
\hline $\begin{array}{l}\text { TEAD1 } \\
\text { TEAD2 } \\
\text { TEAD3 } \\
\text { TEAD4 }\end{array}$ & $\begin{array}{c}11 \mathrm{p} 15.2 \\
19 \mathrm{q} 13.33 \\
6 \mathrm{p} 21.31 \\
12 \mathrm{p} 13.33\end{array}$ & Scalloped & $\begin{array}{l}\text { TEA-domain containing } \\
\text { transcription factor }\end{array}$ \\
\hline
\end{tabular}

C

\begin{tabular}{|c|c|c|c|}
\hline Human gene & $\begin{array}{l}\text { Chromosomal } \\
\text { localization }\end{array}$ & $\begin{array}{c}\text { Drosophila } \\
\text { protein }\end{array}$ & Features \\
\hline $\begin{array}{l}\text { FZD3 } \\
\text { FZD6 }\end{array}$ & $\begin{array}{l}8 \mathrm{p} 21.1 \\
8 \mathrm{q} 22.3\end{array}$ & Frizzled & $\begin{array}{l}\text { Seven-transmembrane-type } \\
\text { WNT receptor }\end{array}$ \\
\hline $\begin{array}{l}\text { DVL1 } \\
\text { DVL2 } \\
\text { DVL3 }\end{array}$ & $\begin{array}{l}1 \mathrm{p} 36.33 \\
17 \mathrm{p} 13.1 \\
3 \mathrm{q} 27.1 \\
\end{array}$ & Dishevelled & Scaffold protein \\
\hline $\begin{array}{l}\text { CELSR1 } \\
\text { CELSR2 } \\
\text { CELSR3 }\end{array}$ & $\begin{array}{c}22 \mathrm{q} 13.31 \\
1 \mathrm{p} 13.3 \\
3 \mathrm{p} 21.31 \\
\end{array}$ & Flamingo & $\begin{array}{l}\text { Seven-transmembrane } \\
\text { protein belonging to the } \\
\text { Cadherin superfamily }\end{array}$ \\
\hline ANKRD6 & 6q15 & Diego & $\begin{array}{l}\text { Ankyrin-repeat-domain } \\
\text { protein }\end{array}$ \\
\hline $\begin{array}{l}\text { VANGL1 } \\
\text { VANGL2 }\end{array}$ & $\begin{array}{l}1 \mathrm{p} 13.1 \\
1 \mathrm{q} 23.2 \\
\end{array}$ & Van Gogh & $\begin{array}{l}\text { Four-transmembrane } \\
\text { protein }\end{array}$ \\
\hline $\begin{array}{l}\text { PRICKLE1 } \\
\text { PRICKLE2 }\end{array}$ & $\begin{array}{r}12 \mathrm{q} 12 \\
3 \mathrm{p} 14.1\end{array}$ & Prickle & LIM-domain protein \\
\hline
\end{tabular}

Figure 1. Drosophila and human Fat signaling components. (A) Drosophila Fat signaling cascades. Drosophila Fat is involved in the Hippo as well as planar cell polarity (PCP) signaling cascades. (B) Human orthologs of Drosophila genes involved in the Fat-Hippo signaling. (C) Human orthologs of Drosophila genes involved in the core PCP signaling.

of Fat and Dachsous cadherins on adjacent cells are reported to preferentially interact in a heterophilic manner $(14,15)$. Four jointed and Discs overgrown are serine/threonine kinases that phosphorylate extracellular domain of Fat in the Golgi and intracellular domain of Fat in the cytoplasm, respectively, to promote Fat signaling (21-24). Heterophilic interaction of Fat and Dachsous cadherins leads to asymmetrical localization of Dachs myosin; depletion of Dachs in the Fat side and accumulation of Dachs in the Dachsous side. Asymmetrical Dachs localization induces PCP through tension anisotrophy-oriented cell rearrangement as well as tumor suppression though Hippo-Salvador-Warts signaling-mediated Yorkie repression (Fig. 1A).

Drosophila components of Fat-Hippo and Fat-PCP signaling cascades are well conserved in mammals, especially in human (Fig. 1B and C). Although precise mechanisms of the Fat-Hippo and Fat-PCP signaling cascades are not completely elucidated, growing pieces of evidence indicate the involvement of the mammalian FAT signaling cascades in embryogenesis and carcinogenesis. In this report, function and cancer genomics of the human FAT family members are reviewed.

\section{FAT family}

The human FAT gene family consists of the FAT1, FAT2, FAT3 and FAT4 genes (28-31). Dunne et al reported complete coding sequence of $F A T 1$ in 1995 . Wu and Maniatis reported complete coding sequence of FAT2 in 2000. Höng et al reported partial coding sequence of FAT3 in 2004 . We reported complete coding sequence of FAT3 and FAT4 in 2006. The FAT1 and FAT3 genes adjoin the MTNRIA and $M T N R 1 B$ genes, respectively. FAT1 is most homologous to FAT3, while MTNR1A is most homologous to MTNRIB. These facts clearly indicate that the FATI-MTNRIA locus on human chromosome 4q35.2 and the FAT3-MTNRIB locus on human chromosome 11q14.3 are paralogous regions within the human genome (31).

Human FAT family genes as well as Drosophila Fat family genes encode large proteins with extracellular Cadherin repeats, EGF-like domains, and Laminin G-like domain(s). Codon 275-352 of FAT2 is homologous to the third Cadherin repeat of FAT1; however, this region of FAT2 was not predicted as the Cadherin repeat using the conserved 
domain search (CDS) program of NCBI. Codon 3790-3828 of FAT1 and codon 3799-3834 of FAT3 are distantly related to the EGF-like domain; however, these regions were not predicted as the EGF-like domain using the CDS program. Because Cadherin repeat and EGF-like domain are defined in a low-stringent manner, it is ambiguous at present whether regions distantly related to Cadherin repeat and EGF-like domain are functional or not. Domain architectures of human FAT1, FAT2 FAT3, FAT4 and Drosophila Fat and Fat-like (Fatl) were illustrated based on the results of the CDS program using each RefSeq as a query sequence. Domain-architecture topologies of the region between Cadherin repeats and the transmembrane domain of human FAT1, FAT2, FAT3 and Drosophila Fatl are a Laminin-G-like domain followed by multiple EGF-like domains, whereas those of human FAT4 and Drosophila Fat are multiple EGF-like domains followed by two Laminin-G-like domains (Fig. 2). Phylogenetic analyses on human and Drosophila FAT family proteins revealed that only FAT4 is located within the same branch as Drosophila Fat (Fig. 2). Together, these facts indicate that human FAT1, FAT2 and FAT3 are orthologs of Drosophila Fatl, and that human FAT4 is the ortholog of Drosophila Fat.

\section{Processing of FAT proteins}

FAT1 and FAT4 undergo the first proteolytic cleavage in the extracellular region by Furin during their maturation step, which gives rise to non-covalent heteodimer consisting of a larger subunit corresponding to the most part of the extracellular region and smaller subunit containing the transmembrane and cytoplasmic regions $(22,32)$. Artificial FAT proteins undergo the second proteolytic cleavage by $\gamma$-secretase and the release of intracellular region, which is similar to the ligand-dependent processing of NOTCH receptors (33). However, evidence of the ligand-dependent second cleavage of endogenous FAT proteins remains unclear.

\section{Signaling and function of FAT1 and FAT4}

Dachsous1 (DCHS1) and Dachsous2 (DCHS2) are mammalian orthologs of Drosophila Dachsous (Fig. 1B); however, heterophilic interaction between extracellular regions of FAT1 and Dachsous1/2 remains unknown. On the other hand, intracellular region of FAT1 directly interacts with Ena/VASP, HOMER, KIF5C and Scribble proteins (34-37). Ena/VASP and HOMER are EVH1-domain proteins binding to the cytoplasmic FPPPPEDF motif of Fat 1 in a mutually competitive manner. Because Ena/VASP proteins inhibit actin capping and induce actin polymerization, Fat1-mediated recruitment of Ena/VAPS proteins to the leading edge of lamellipodia and the tip of filopodia results in the promotion of cell migration $(34,35)$. Scribble proteins are scaffold proteins with multiple PDZ domains binding to the C-terminal HTEV motif of Fat1. Fat1 and Scribble are synergistically involved in the suppression of cystogenesis phenotype through the inhibition of Yap1 signaling (37). Fat1 knockdown in vascular smooth muscle cells results in decreased migration and enhanced proliferation (38). FAT1 is involved in promotion of actin-mediated cell migration as well as inhibition of YAP1-mediated cell proliferation (Fig. 3A).

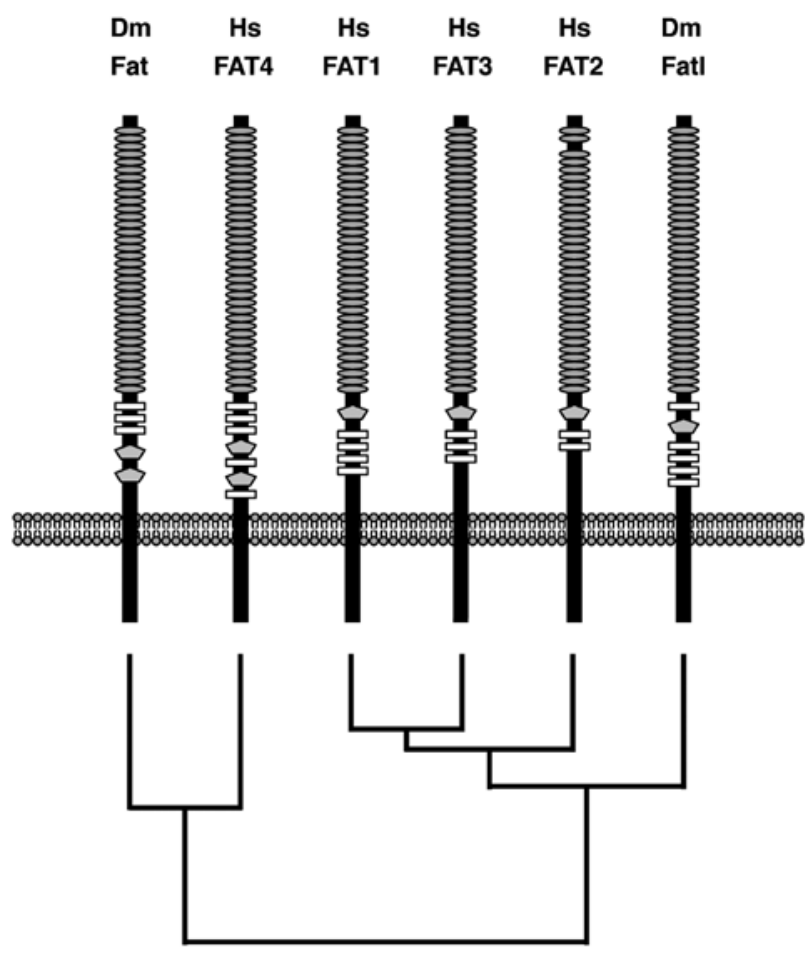

Figure 2. Domain architectures and phylogenetic tree of human and Drosophila Fat family members. Hs, human; Dm, Drosophila; grey oval, Cadherin repeat; open rectangle, EGF-like domain; gray pentagon, Laminin G-like domain. Human FAT1, FAT2 and FAT3 are orthologs of Drosophila Fat-like (Fatl), whereas human FAT4 is the ortholog of Drosophila Fat.

Fat4 heterophilically interacts with Dachsous1 at the apical portion of cell-cell boundaries of neural progenitor cells, where intracellular region of Fat4 directly interacts with Mpdz/Mupp1-Mpp5/Pals1 complex (39). Mpp1, Mpp2, Mpp3, Mpp4, Mpp5, Mpp6/Pals2 and Mpp7 are membrane-associated guanylate kinase (MAGUK) homologs of Drosophila Stardust (Sdt), which is involved in the maintenance of apicobasal polarity in epithelial tissues (40). Fat4 knockout mice die at birth, which are manifested by stereocilia disorientation in the inner ear, loop tail, broader neural tube and renal cysts (41). Disorientation of cochlear hair cells is the typical phenotype of the mammalian PCP defect in Vangl2, Celsrl or Dvll/Dvl2 mutant mice (42). Loop tail and neural tube abnormalities are also observed in Vangl2 mutant mice (43) and renal cystogenesis is synergistically enhanced in $\mathrm{Fat}^{-/-}$Vangl2 $^{-/+}$mice (42). Fat4 knockdown in neural tube results in an increase of a subset of neural progenitors and differentiated $\operatorname{Lim} 1^{+} / \mathrm{Lim} 2^{+}$ neurons via downregulation of Yap1 phosphorylation (44). FAT4 is involved in the maintenance of PCP as well as inhibition of YAP1-mediated cell proliferation (Fig. 3A).

\section{Cancer genomics of $F A T$ family genes}

The human FAT1 gene is homozygously deleted in $23 \%$ of oral cancer cell lines and in $80 \%$ of primary oral cancer cases and FAT1 mRNA expression is repressed in oral cancer cell lines due to homozygous deletion and/or promoter $\mathrm{CpG}$ hypermethylation (45). Loss of heterozygosity ( $\mathrm{LOH})$ of the FAT1 gene occurs in $42 \%$ of low grade diffuse astrocytoma and $63 \%$ of 


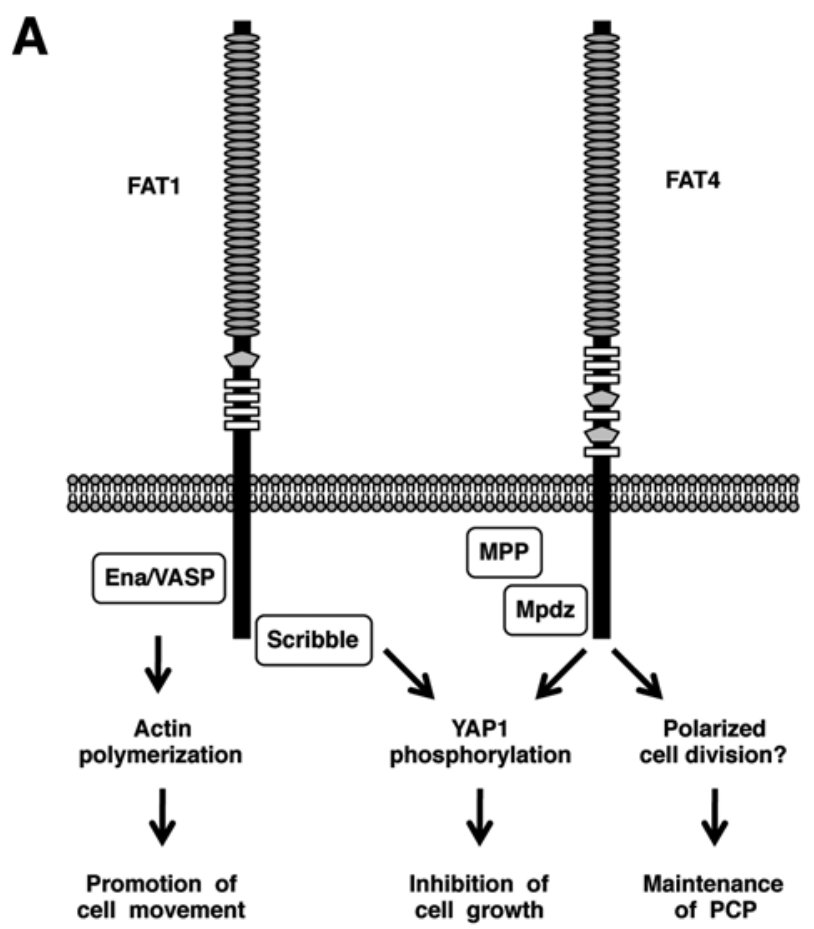

B

\begin{tabular}{|lll|}
\hline FAT & Human cancers & Omics alterations and cancer biology \\
\hline & Oral cancer & $\begin{array}{l}\text { Homozygous deletion \& mRNA downregulation } \\
\text { Promoter hypermethylation \& mRNA downregulation }\end{array}$ \\
\cline { 2 - 3 } FAT1 & $\begin{array}{l}\text { Astrocytoma and } \\
\text { glioblastoma }\end{array}$ & Loss of heterozygosity \\
\cline { 2 - 3 } & Breast cancer & mRNA \& protein downregulation in invasive cancer \\
\cline { 2 - 3 } & Melanoma & Aberrant processing of FAT1 protein \\
\cline { 2 - 3 } & Leukemia & mRNA upregulation in AML, preB-ALL \& T-ALL \\
& & Poor prognosis in preB-ALL with FAT1 upregulation \\
\cline { 2 - 3 } & Pancreatic cancer & Point mutation \\
\hline FAT2 & HNSCC & Point mutation \\
\hline \multirow{3}{*}{ FAT4 } & Pancreatic cancer & Point mutation \\
\cline { 2 - 3 } & Breast cancer & Promoter hypermethylation \& mRNA downregulation \\
\cline { 2 - 3 } & Lung cancer & Promoter hypermethylation \& mRNA downregulation \\
\cline { 2 - 3 } & HNSCC & Point mutation \\
\hline & HCC & Point mutation \\
\hline & Melanoma & Point mutation \\
\hline & Gastric cancer & Loss of heterozygosity \& point mutation \\
\hline
\end{tabular}

Figure 3. Function and cancer genomics of FATs. (A) FAT1 and FAT4 signaling cascades. FAT1 interacts with Ena/VASP to induce actin polymerization at lamellipodia and filopodia, which is involved in the promotion of cell movement. FAT1 interacts with Scribble to induce YAP1 phosphorylation, which is involved in the inhibition of cell growth. FAT4 interacts with MPDZ (MUPP1) to recruit membrane-associated guanylate kinase MPP5 (PALS1). FAT4 is involved in the maintenance of PCP as well as the inhibition of cell proliferation. (B) Omics alterations of FAT family members in human cancers. AML, acute myeloid leukemia; ALL, acute lymphoblastic leukemia; HNSCC, head and neck squamous cell carcinoma; HCC, hepatocellular carcinoma.

glioblastoma multiforme (46). FAT1 mRNA level in ductal carcinoma in situ is significantly higher than that in invasive breast cancer and FATl knockdown promotes progression from ductal carcinoma in situ to invasive breast cancer (47). FAT1 mRNA expression is upregulated in $11 \%$ of acute myeloid leukemia (AML), 29\% of preB acute lymphoblastic leukemia (ALL) and 63\% of T-ALL, and FAT1 upregulation in preB-ALL is associated with shorter relapse-free survival as well as shorter overall survival (48). FAT1 immunoreactivity is strong in $29 \%$ of cholangiocarcinoma (49).

The mouse Fat 3 mRNA is significantly downregulated in lung adenocarcinoma occurred in transgenic mice expressing wild-type Rafl transgene under the control of the human $S P-C$ (surfactant protein C) promoter (50).

The mouse Fat4 gene is inactivated owing to $\mathrm{LOH}$ and promoter $\mathrm{CpG}$ hypermethylation in subcutaneous tumor induced by Cre/LoxP-mediated random chromosomal deletion (51). Tumor growth is inhibited by re-introduction of Fat 4 gene into cells derived from the cutaneous tumor. Relative YAP1 activity is significantly upregulated as a result of Fat4 repression.

The human FAT4 mRNA expression is repressed in 3 out of 6 breast cancer cell lines and in 3 out of 5 cases of primary breast cancers, partially due to promoter $\mathrm{CpG}$ hypermethylation (51). FAT4 promoter is hypermethylated in 7 out of 18 cases of lung adenocarcinoma (stage I) and FAT4 mRNA is downregulated in 18 out of 23 cases of non-small cell lung tumors (stage I or II) (52).

Using the whole-exome sequencing approach, non-synonymous mutations of human FAT1, FAT3 and FAT4 genes are detected in 1 each, and 2 out of 24 pancreatic cancer samples, respectively (53). Non-synonymous mutations of human $F A T 2$ and FAT4 genes are detected in 1 and 2 out of 32 cases of head and neck squamous cell carcinoma (HNSCC), respectively (54). Non-synonymous FAT4 mutation is detected in 1 out of 10 cases of hepatocellular carcinoma using the wholeexome sequencing approach (55). Non-synonymous FAT4 mutations are also detected in 4 out of 6 cases of melanomas using the whole-exome sequencing approach and in 2 out of additional 9 cases of melanomas using the candidate-exons sequencing approach (56). Non-synonymous FAT4 mutations are detected in 2 out of 15 cases of gastric cancers using the whole-exome approach and in 4 out of additional 95 cases of gastric cancers using the candidate-exon approach (57). Among the human FAT gene family, FAT4 gene is recurrently mutated in several types of human cancers, such as melanoma (40\%), pancreatic cancer $(8 \%)$, HNSCC $(6 \%)$ and gastric cancer (5\%).

\section{Conclusion}

FAT1 is downregulated in oral cancer and invasive breast cancer due to deletion and/or epigenetic silencing, whereas FAT1 is upregulated in leukemia and prognosis of preB-ALL with FAT1 upregulation is poor. FAT4 is mutated in several types of human cancer, such as melanoma, pancreatic cancer and gastric cancer (Fig. 3B). FAT1 and FAT4 suppress tumor growth through Hippo signaling activation, while FAT1 promotes tumor migration through actin polymerization at lamellipodia and filopodia. Together, these facts indicate that FAT1 is tumor suppressive or oncogenic in a context-dependent manner and that FAT4 is preferentially tumor suppressive. 


\section{Perspectives}

Drosophila Fat is involved in the tumor suppression via phosphorylation-mediated functional inhibition of Yorkie through indirect activation of the Expanded-Hippo-Warts signaling cascade (Fig. 1A). Expanded interacts with Merlin and Kibra to activate the Hippo signaling cascade, while Salvador and Mats are involved in the regulation of Hippo and Warts kinases, respectively (Fig. 1A). FRMD1 and FRMD6 are human orthologs of Drosophila Expanded; NF2 is the human ortholog of Drosophila Merlin; WWC1 and WWC2 are human orthologs of Drosophila Kibra; SAV1 is the human ortholog of Drosophila Salvador; STK3 and STK4 are human orthologs of Drosophila Hippo; MOB1A and MOB1B are human orthologs of Drosophila Mats; LATS1 and LATS2 are human orthologs of Drosophila Warts; YAP1 and WWTR1 (TAZ) are human orthologs of Drosophila Yorkie (Fig. 1B). Copy number aberration, translocation and point mutation of human FAT1, FAT2, FAT3, FAT4, FRMD1, FRMD6, NF2, WWC1, WWC2, SAV1, STK3, STK4, MOB1A, $M O B 1 B, L A T S 1, L A T S 2, Y A P 1$ and WWTR1 genes should be comprehensively investigated in various types of human cancers using high-throughput sequencing technology to elucidate the mutation landscape of the FAT-Hippo signaling cascades.

YAP1 and WWTR1 directly interact with $\beta$-catenin and Hippo signaling-induced phosphorylation of YAP1 results in the inhibition of the canonical WNT signaling cascade (58). WNT signaling cascades crosstalk with FGF, Notch, Hedgehog and TGF $\beta /$ BMP signaling cascades to constitute the stem-cell signaling network (59). Because Hippo-YAP1/WWTR1 signaling cascade is located at the crossroads of adhesion signaling, G-protein-coupled receptor (GPCR) signaling, receptor tyrosine kinase (RTK) signaling and stem cell biology (12,60-62), cancer genomics of the FAT signaling cascades could be applied for diagnostics, prognostics and therapeutics in the era of personalized medicine.

\section{Acknowledgements}

This study was supported in part by National Cancer Center Research and Development Fund.

\section{References}

1. Bryant PJ, Huettner B, Held LI Jr, Ryerse J and Szidonya J: Mutations at the fat locus interfere with cell proliferation control and epithelial morphogenesis in Drosophila. Dev Biol 129: 541-554, 1988.

2. Woods DF and Bryant PJ: The discs-large tumor suppressor gene of Drosophila encodes a guanylate kinase homolog localized at septate junctions. Cell 66: 451-464, 1991.

3. Strand D, Raska I and Mechler BM: The Drosophila lethal(2) giant larvae tumor suppressor protein is a component of the cytoskeleton. J Cell Biol 127: 1345-1360, 1994.

4. Justice RW, Zilian O, Woods DF, Noll M and Bryant PJ: The Drosophila tumor suppressor gene warts encodes a homolog of human myotonic dystrophy kinase and is required for the control of cell shape and proliferation. Genes Dev 9: 534-546, 1995.

5. Bilder D and Perrimon N: Localization of apical epithelial determinants by the basolateral PDZ protein Scribble. Nature 403: 676-680, 2000.

6. Tapon N, Harvey KF, Bell DW, et al: salvador promotes both cell cycle exit and apoptosis in Drosophila and is mutated in human cancer cell lines. Cell 110: 467-478, 2002.
7. Pantalacci S, Tapon N and Léopold P: The Salvador partner Hippo promotes apoptosis and cell-cycle exit in Drosophila. Nat Cell Biol 5: 921-927, 2003.

8. Bryant PJ, Watson KL, Justice RW and Woods DF: Tumor suppressor genes encoding proteins required for cell interactions and signal transduction in Drosophila. Dev Suppl pp239-249, 1993.

9. Hariharan IK and Bilder D: Regulation of imaginal disc growth by tumor-suppressor genes in Drosophila. Annu Rev Genet 40: $335-361,2006$.

10. Saucedo LJ and Edgar BA: Filling out the Hippo pathway. Nat Rev Mol Cell Biol 8: 613-621, 2007.

11. Reddy BV and Irvine KD: The Fat and Warts signaling pathways: new insights into their regulation, mechanism and conservation. Development 135: 2827-2838, 2008.

12. Pan D: The hippo signaling pathway in development and cancer. Dev Cell 19: 491-505, 2010.

13. Genevet A and Tapon N: The Hippo pathway and apico-basal cell polarity. Biochem J 436: 213-224, 2011.

14. Yang CH, Axelrod JD and Simon MA: Regulation of Frizzled by fat-like cadherins during planar polarity signaling in the Drosophila compound eye. Cell 108: 675-688, 2002.

15. Strutt H and Strutt D: Nonautonomous planar polarity patterning in Drosophila: dishevelled-independent functions of frizzled. Dev Cell 3: 851-863, 2002.

16. Axelrod JD: Progress and challenges in understanding planar cell polarity signaling. Semin Cell Dev Biol 20: 964-971, 2009.

17. Djiane A and Mlodzik M: The Drosophila GIPC homologue can modulate myosin based processes and planar cell polarity but is not essential for development. PLoS One 5: e11228, 2010

18. Axelrod JD, Miller JR, Shulman JM, Moon RT and Perrimon N: Differential recruitment of Dishevelled provides signaling specificity in the planar cell polarity and Wingless signaling pathways. Genes Dev 12: 2610-2622, 1998.

19. Mlodzik M: Planar cell polarization: do the same mechanisms regulate Drosophila tissue polarity and vertebrate gastrulation? Trends Genet 18: 564-571, 2002.

20. Katoh M: WNT/PCP signaling pathway and human cancer (Review). Oncol Rep 14: 1583-1588, 2005.

21. Ishikawa HO, Takeuchi H, Haltiwanger RS and Irvine KD: Four-jointed is a Golgi kinase that phosphorylates a subset of cadherin domains. Science 321: 401-404, 2008.

22. Sopko R and McNeill H: The skinny on Fat: an enormous cadherin that regulates cell adhesion, tissue growth, and planar cell polarity. Curr Opin Cell Biol 21: 717-723, 2009.

23. Thomas $C$ and Strutt D: The roles of the cadherins Fat and Dachsous in planar polarity specification in Drosophila. Dev Dyn 241: 27-39, 2012.

24. Bosveld F, Bonnet I, Guirao B, et al: Mechanical control of morphogenesis by Fat/Dachsous/Four-jointed planar cell polarity pathway. Science 336: 724-727, 2012.

25. Mahoney PA, Weber U, Onofrechuk P, Biessmann H, Bryant PJ and Goodman CS. The fat tumor suppressor gene in Drosophila encodes a novel member of the cadherin gene superfamily. Cell 67: 853-868, 1991.

26. Tanoue $\mathrm{T}$ and Takeichi M: New insights into Fat cadherins. J Cell Sci 118: 2347-2353, 2005.

27. Hulpiau P and van Roy F: Molecular evolution of the cadherin superfamily. Int J Biochem Cell Biol 41: 349-369, 2009.

28. Dunne J, Hanby AM, Poulsom R, et al: Molecular cloning and tissue expression of FAT, the human homologue of the Drosophila fat gene that is located on chromosome 4q34-q35 and encodes a putative adhesion molecule. Genomics 30: 207-223, 1995.

29. Wu Q and Maniatis T: Large exons encoding multiple ectodomains are a characteristic feature of protocadherin genes. Proc Natl Acad Sci USA 97: 3124-3129, 2000.

30. Höng JC, Ivanov NV, Hodor P, et al: Identification of new human cadherin genes using a combination of protein motif search and gene finding methods. J Mol Biol 337: 307-317, 2004.

31. Katoh Y and Katoh M: Comparative integromics on FAT1, FAT2, FAT3 and FAT4. Int J Mol Med 18: 523-528, 2006.

32. Sadeqzadeh E, de Bock CE, Zhang XD, et al: Dual processing of FAT1 cadherin protein by human melanoma cells generates distinct protein products. J Biol Chem 286: 28181-28191, 2011.

33. Magg T, Schreiner D, Solis GP, Bade EG and Hofer HW: Processing of the human protocadherin Fatl and translocation of its cytoplasmic domain to the nucleus. Exp Cell Res 307: 100-108, 2005.

34. Tanoue T and Takeichi M: Mammalian Fat1 cadherin regulates actin dynamics and cell-cell contact. J Cell Biol 165: 517-528, 2004. 
35. Moeller MJ, Soofi A, Braun GS, et al: Protocadherin FAT1 binds Ena/VASP proteins and is necessary for actin dynamics and cell polarization. EMBO J 23: 3769-3779, 2004.

36. Schreiner D, Müller K and Hofer HW: The intracellular domain of the human protocadherin hFat1 interacts with Homer signalling scaffolding proteins. FEBS Lett 580: 5295-5300, 2006.

37. Skouloudaki K, Puetz M, Simons M, et al: Scribble participates in Hippo signaling and is required for normal zebrafish pronephros development. Proc Natl Acad Sci USA 106: 8579-8584, 2009.

38. Hou R, Liu L, Anees S, Hiroyasu S and Sibinga NE: The Fat1 cadherin integrates vascular smooth muscle cell growth and migration signals. J Cell Biol 173: 417-429, 2006.

39. Ishiuchi T, Misaki K, Yonemura S, Takeichi M and Tanoue $\mathrm{T}$ : Mammalian Fat and Dachsous cadherins regulate apical membrane organization in the embryonic cerebral cortex. J Cell Biol 185: 959-967, 2009.

40. Katoh $\mathrm{M}$ and Katoh M: Identification and characterization of human MPP7 gene and mouse Mpp7 gene in silico. Int $\mathrm{J}$ Mol Med 13: 333-338, 2004.

41. Saburi S, Hester I, Fischer E, et al: Loss of Fat4 disrupts PCP signaling and oriented cell division and leads to cystic kidney disease. Nat Genet 40: 1010-1015, 2008.

42. Jones $\mathrm{C}$ and Chen P: Planar cell polarity signaling in vertebrates. Bioessays 29: 120-132, 2007.

43. Kibar Z, Vogan KJ, Groulx N, Justice MJ, Underhill DA and Gros P: Ltap, a mammalian homolog of Drosophila Strabismus/Van Gogh, is altered in the mouse neural tube mutant Loop-tail. Nat Genet 28: 251-255, 2001.

44. van Hateren NJ, Das RM, Hautbergue GM, Borycki AG, Placzek $M$ and Wilson SA: FatJ acts via the Hippo mediator Yap1 to restrict the size of neural progenitor cell pools. Development 138: 1893-1902,2011.

45. Nakaya K, Yamagata HD, Arita N, et al: Identification of homozygous deletions of tumor suppressor gene $F A T$ in oral cancer using CGH-array. Oncogene 26: 5300-5308, 2007.

46. Chosdol K, Misra A, Puri S, et al: Frequent loss of heterozygosity and altered expression of the candidate tumor suppressor gene ' $F A T$ ' in human astrocytic tumors. BMC Cancer 9: 5, 2009.

47. Lee S, Stewart S, Nagtegaal I, et al: Differentially expressed genes regulating the progression of ductal carcinoma in situ to invasive breast cancer. Cancer Res 72: 4574-4586, 2012.

48. de Bock CE, Ardjmand A, Molloy TJ, et al: The Fat1 cadherin is overexpressed and an independent prognostic factor for survival in paired diagnosis-relapse samples of precursor B-cell acute lymphoblastic leukemia. Leukemia 26: 918-926, 2012.
49. Settakorn J, Kaewpila N, Burns GF and Leong AS: FAT, E-cadherin, $\beta$-catenin, HER $2 /$ neu, Ki67 immuno-expression, and histological grade in intrahepatic cholangiocarcinoma. J Clin Pathol 58: 1249-1254, 2005.

50. Rohrbeck A and Borlak J: Cancer genomics identifies regulatory gene networks associated with the transition from dysplasia to advanced lung adenocarcinomas induced by c-Raf-1. PLoS One 4: e7315, 2009.

51. Qi C, Zhu YT, Hu L and Zhu YJ: Identification of Fat4 as a candidate tumor suppressor gene in breast cancers. Int J Cancer 124: 793-798, 2009.

52. Rauch TA, Wang Z, Wu X, Kernstine KH, Riggs AD and Pfeifer GP: DNA methylation biomarkers for lung cancer. Tumour Biol 33: 287-296, 2012.

53. Jones S, Zhang X, Parsons DW, et al: Core signaling pathways in human pancreatic cancers revealed by global genomic analyses. Science 321: 1801-1806, 2008.

54. Agrawal N, Frederick MJ, Pickering CR, et al: Exome sequencing of head and neck squamous cell carcinoma reveals inactivating mutations in NOTCH1. Science 333: 1154-1157, 2011.

55. Li M, Zhao $\mathrm{H}$, Zhang $\mathrm{X}$, et al: Inactivating mutations of the chromatin remodeling gene ARID2 in hepatocellular carcinoma. Nat Genet 43: 828-829, 2011

56. Nikolaev SI, Rimoldi D, Iseli C, et al: Exome sequencing identifies recurrent somatic $M A P 2 K 1$ and $M A P 2 K 2$ mutations in melanoma. Nat Genet 44: 133-139, 2011.

57. Zang ZJ, Cutcutache I, Poon SL, et al: Exome sequencing of gastric adenocarcinoma identifies recurrent somatic mutations in cell adhesion and chromatin remodeling genes. Nat Genet 44: $570-574,2012$.

58. Imajo M, Miyatake K, Iimura A, Miyamoto A and Nishida E: A molecular mechanism that links Hippo signalling to the inhibition of Wnt/ $\beta$-catenin signalling. EMBO J 31: 1109-1122, 2012.

59. Katoh M and Katoh M: WNT signaling pathway and stem cell signaling network. Clin Cancer Res 13: 4042-4045, 2007.

60. Yu FX, Zhao B, Panupinthu N, et al: Regulation of the Hippo-YAP pathway by G-Protein-coupled receptor signaling. Cell 150: 780-791, 2012.

61. Huang W, Lv X, Liu C, et al: The N-terminal phosphodegron targets TAZ/WWTR1 protein for SCF $\beta$-TrCP-dependent degradation in response to phosphatidylinositol 3-kinase inhibition. J Biol Chem 287: 26245-26253, 2012.

62. Cordenonsi M, Zanconato F, Azzolin L, et al: The Hippo transducer TAZ confers cancer stem cell-related traits on breast cancer cells. Cell 147: 759-772, 2011. 